\title{
ARTICLE
}

\section{Impact of exogenous alpha tocopherol on peanut seedlings (Arachis hypogaea L.) treated by norflurazon}

\author{
Imene Manaa*, Reda Djebbar, Ouzna Abrous-Belbachir \\ * Laboratory of Biology and Physiology of Organisms (LBPO), Faculty of Biological Sciences, University of Sciences \\ and Technology Houari Boumediene, El Alia, Bab Ezzouar, Algeria
}

\section{ABSTRACT}

Norflurazon $100 \mu \mathrm{M}$ alone or in combination with a-tocopherol $(0.25$ $\mathrm{mM}$ ) was applied in pre-emergence of peanut seedlings (Arachis hypogaea L.). Norflurazon treatment allowed to partially or totally photobleach plants which were noticeably smaller than the control. Norflurazon impaired the photosynthetic activity by decreasing photosynthetic pigments (carotenoids and chlorophylls) and by reducing quantities of soluble sugar. The determination of malondialdehyde (MDA) showed that its content was higher in treated plants in relation with enhancement of reactive oxygen species by the herbicide and decreased the endogenous a-tocopherol. The addition of exogenous a-tocopherol reduced the damage done by the herbicide at the membrane level because of the MDA content was less important than in norflurazon treated seedlings. Furthermore, the norflurazon decreased the glutathione S-transferase (GST) activity in the leaves and the roots of peanut seedlings, while it increased the level of reduced glutathione. This activity decreased even more with the application of exogenous a-tocopherol in combination with the herbicide. The herbicide alone or in association with the antioxidant a-tocopherol increased ascorbic acid content. The supplementation of a-tocopherol did not decrease the phytotoxicity of norflurazon although we observed a decrease in MDA content.

Acta Biol Szeged 63(2):125-133 (2019)
\end{abstract}

\section{KEY WORDS}

Arachis hypogaea carotenoids lipid peroxidation norflurazon a-tocopherol

\section{ARTICLE INFORMATION}

Submitted

13 August 2019

Accepted

19 October 2019

*Corresponding author

E-mail: oabrous@yahoo.fr

\section{Introduction}

Environmental stresses like biotic and abiotic factors, adversely affect the productivity and quality of agriculturally important crops. To improve the yield of peanuts, pesticides are usually used to protect crops from weeds, diseases and pests. Unfortunately, the agricultural products can be contaminated with pesticides by the improper and abusive use of them as well as due to the plants' uptake of them from contaminated water and soil. Unlike hydrocarbons, pesticides are deliberately abused by humans in order to increase agricultural yields.

Abiotic stresses are known to cause damage to plants, either directly or indirectly through Reactive Oxygen Species (ROS) formation (Jung et al. 2000). Oxidative stress, characterized by excess accumulation of ROS, could result from various environmental stresses such as herbicides (Doulis 1994). The ROS are toxic and may result in a series of damages to plant metabolism. It damages photosynthetic components, inactivates proteins, destroys cell membrane structures and lower membrane permeability by causing lipid peroxidation (Mittler et al. 2004). ROS are also sensed by the plant cells and can act as a signal molecule that can induce ROS-detoxifying responses (Karuppanapandian et al. 2011). Norflurazon is a systemic herbicide which penetrates the plant through the roots. It is able to remotely reach the sensitive cell sites by means of the conducting vessels (Scalla 1991).

Norflurazon is a bleaching herbicide used in many research laboratories; the target of norflurazon is the phytoene desaturase, a key enzyme of carotenoid biosynthetic pathway (Breitenbach et al. 2001). Carotenoid deficiency causes oxidative stress due to significant increase of ROS content (Jung et al. 2000). So, carotenoids are not only accessory pigments in the photosynthetic apparatus, they also act as photoprotective agents by absorbing excess energy of triplet excited states of chlorophyll $\left({ }^{3} \mathrm{Chl}\right)$ and detoxifying of singlet oxygen ${ }^{1} \mathrm{O}_{2}$ (Vencill 2002). Norflurazon also inhibits the unsaturation of chloroplast lipids (Abrous-Belbachir et al. 2009).

Plants possess various antioxidants systems to cope with the oxidative stress conditions. These include non enzymatic antioxidants such as carotenoids, tocopherols, ascorbic acid, glutathione, phenolic compounds and antioxidants enzymes such as superoxide dismutases (SOD), catalases, and the ascorbate-glutathione cycle enzymes (Apel and Hirt 2004). In plants, herbicides can be me- 
tabolized by a sequential action of several enzymes as cytochrome P450 (CYP450) and glutathione S-transferases (GSTs). Glutathione S-transferases catalyze the conjugation of reduced glutathione (GSH) with some xenobiotic compounds (Higgins and Hayes 2011).

Under the herbicide treatment, plants initiate some defensive and protective mechanisms. One of them is associated with changes in concentrations of vitamins including $\alpha$-tocopherol and ascorbic acid. Exogenous vitamins have been studied in relation to damage generated by the herbicides and other forms of environmental stresses. Tocopherols are known as tocochromanols, a group of lipophilic antioxidants that are exclusively synthesized by higher plants. Of the two classes of tocochromanols, tocopherols occur more widely in plants and the alpha form is typically abundant in the leaves (Szymańska and Kruk 2008). $\alpha$-tocopherol, which is located within chloroplast membranes, has gotten the highest antioxidant activity against lipid oxidation (Mène-Saffrané and DellaPenna 2010); it can quench oxygen radicals, stabilize cell membranes and protect chlorophyll (Hess 1993). Tocopherol termination of lipid peroxidation chain is where $\alpha$-tocopherol donates hydrogen to lipid radicals and turns it to a hydroperoxide molecule, which is then either reduced to an alcohol or further oxidized to other compounds (e.g., n-hexanal, jasmonic acid, and traumatic acid) depending on the size and nature of the lipid chain.

The $\alpha$-tocopherol radical formed after this process is either recycled back to $\alpha$-tocopherol by ascorbate or forms other oxidized products (Munné-Bosch 2005). The presence of $\alpha$-tocopherol can affect intracellular signaling by directly interacting with components of the signaling cascade or indirectly by controlling concentrations of secondary oxidation products (Sattler et al. 2004). Numerous reports are available about attempts that have been made to reduce oxidative stress in plants by exogenous application of tocopherols (Oertli 1987). Awad et al. (2005) reported that, exogenous application of $\alpha$-tocopherol enhanced date palm plantlets' tolerance to environmental stresses. Peanut (Arachis hypogaea L.) is a dicotyledonous plant and an oil seed crop widely cultivated in many areas across the world. It is grown under different agro-climatic zones of tropical and subtropical regions of Asia, Africa, North and South America (Bhatnagar-Mathur et al. 2007). Peanut is an important source of edible oil, dietary minerals, vitamins and proteins. In Algeria, this annual legume is grown in different regions, especially in the south.

\section{Materials and Methods}

\section{Used chemicals}

Norflurazon (4-chloro-5-methylamino-2a,a,a-trifluo-
romethylphenyl-3-(2H) pyridazinone; San 9789) was used as a pre-emergence herbicide. It is commercially named Zorial and the recommended use is $2000 \mathrm{~g} / \mathrm{ha}$. The concentration here $(100 \mu \mathrm{M})$ is similar, to the recommended doses. Vitamin E ( $\alpha$-tocopherol or 5,7,8-trimethyl-tocol) was used as exogenous antioxidant. It was purchased from (Fluka). The concentration used was $0.25 \mathrm{mM}$.

\section{Plant growth conditions and treatments}

Peanut (A. hypogaea L.) seeds were surface sterilized with diluted sodium hypochlorite $12 \%$ for $10 \mathrm{~min}$ and then rinsed thoroughly with water. Seed germination was induced by incubation on water-soaked paper at $27^{\circ} \mathrm{C}$ for 3 days. Once germinated, seedlings were transplanted into plastic containers containing $160 \mathrm{~g}$ of soil. The treatment was carried out by watering the seeds sown in pots with solutions of norflurazon $(100 \mu \mathrm{M})$ or in combination with $\alpha$-tocopherol $(0.25 \mathrm{mM})$. Plants were watered once with $20 \mathrm{ml}$ of norflurazon alone or with norflurazon supplemented with $\alpha$-tocopherol. Controls were irrigated with $20 \mathrm{ml}$ of water. From the second day, plants (control and treated), were grown in a greenhouse and were regularly watered with an appropriate volume of water.

\section{Estimation of growth and dry matter mass}

The length of aerial parts was measured from the base of the stems (crown) to the apical bud for 30 days. Dry matter mass was obtained after total desiccation of aerial parts at $60^{\circ} \mathrm{C}$.

\section{Measurement of the leaf surface}

The leaf surface is calculated as follows: $1 \mathrm{~cm}^{2}$ of a paper layer is taken and then weighed using a precision balance $(0.1 \mathrm{mg})$. The shape of the leaf is drawn on the same type of paper, cut and then weighted. The leaf surface $(\mathrm{X})$ is deducted by the following formula:

$$
X=\frac{\mathrm{mf}}{\mathrm{mp}}
$$

Mf: mass of paper cut; Mp: mass of $1 \mathrm{~cm}^{2}$ of the paper

\section{Photosynthetic pigments content}

Total pigments from fresh leaves were extracted in $80 \%$ (v/v) acetone. Pigments content were determined by absorbance spectrophotometry as recommended by Lichtenthaler (1987).

\section{Soluble sugars content}

Soluble carbohydrates content was determined according to the method described by McCready et al. (1950). Measurements were performed at $630 \mathrm{~nm}$. Soluble carbohydrate concentration was determined using a glucose 

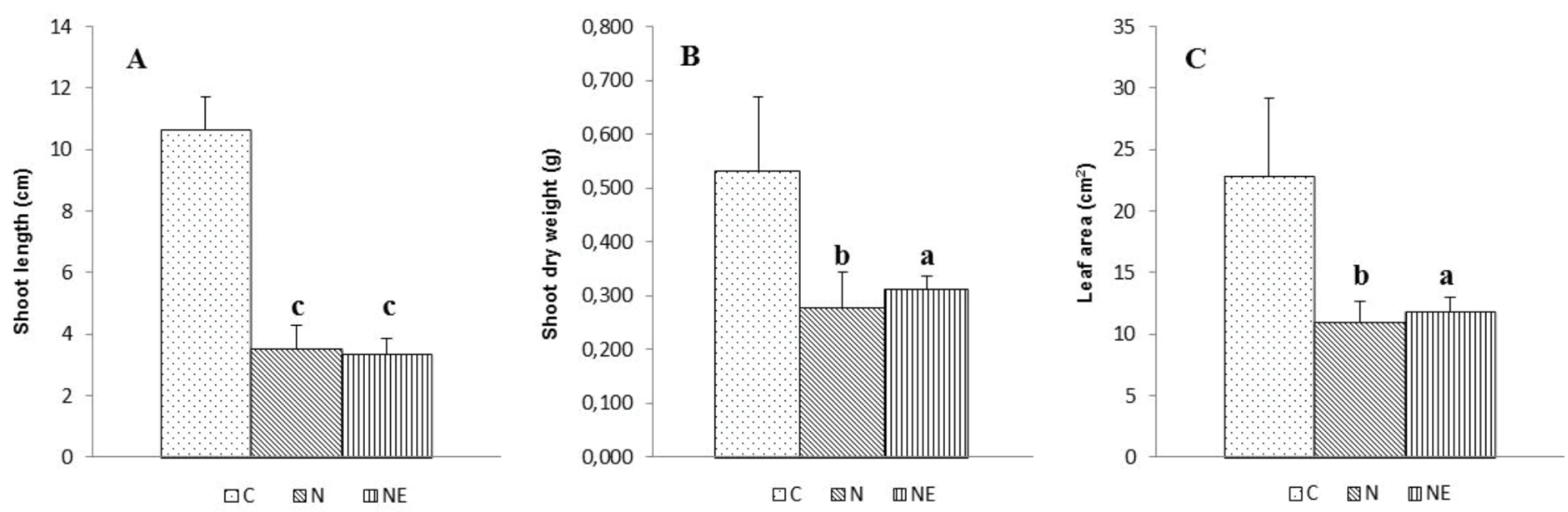

Figure 1. Effects of norflurazon on peanut growth. C: control; N: $100 \mu \mathrm{M}$ norflurazon; NE: $100 \mu \mathrm{M}$ norflurazon +0.25 mM a-tocopherol. Letters indicate the significant differences between the treatments and the control. a: significant $(P<0.05)$; b: very significant $(P<0.01)$; c: highly significant $(P<0.001)$.

standard curve.

\section{Lipid peroxidation analysis}

Lipid peroxidation was determined by measuring the content of MDA using a TBARS (Thiobarbituric Acid Reactive Substances) assay as described by Sinnhuber and $\mathrm{Yu}$ (1958). The absorbance of the supernatant (TBA-MDA complex) was measured at $532 \mathrm{~nm}$. The concentration of TBARS was calculated by using tetramethoxy-propane as a standard.

\section{Determination of lipid-soluble antioxidant a-tocopherol}

$\alpha$-tocopherol was determined by HPLC, as described by Szymańska and Kruk (2008). The chromatographic conditions of analysis were as follows: the mobile phase was acetonitrile:dichloromethane:methanol (70:20:10, $\mathrm{v} / \mathrm{v} / \mathrm{v}$ ), flow rate of $1 \mathrm{ml} \mathrm{min}^{-1}$, UV detection at $292 \mathrm{~nm}$, $\mathrm{C}_{18}$ reverse-phase column $(220 \times 4.6 \mathrm{~mm})$. The levels of $\alpha$-tocopherol were calculated using $\alpha$-tocopherol as a standard.

\section{Soluble antioxidants content ascorbate and glutathione}

Ascorbate content was determined as described by Hodges et al. (1996) by the measure of absorbance at $525 \mathrm{~nm}$. The ascorbate concentration was calculated from the standard curve using ascorbic acid. The GSH assay was based on the colorimetric method of Ellman (1959). Absorbance at $412 \mathrm{~nm}$ was determined by spectrophotometry. The concentrations were deducted from a standard curve established with reduced glutathione.

\section{Glutathione S-transferase activity}

GST activity was performed according to Habig et al. (1974), based on the reaction of conjugation between GSH and 1-chloro-2,4-dinitrobenzene (CDNB) in the presence of GST. This activity was measured at $340 \mathrm{~nm}$ using the molar extinction coefficient $\varepsilon=9.6 \mathrm{M}^{-1} \mathrm{~cm}^{-1}$. Protein content was determined by the method of Bradford (1976) using bovine serum albumin (BSA) as a protein standard.

\section{Statistical analysis}

The results are obtained from three independent experiments. The statistical analysis was carried out by ANOVA analysis and Student's t-test.

\section{Results}

\section{Morphological analysis}

Plants growing in norflurazon-polluted soil were depigmented. Bleaching symptoms had begun at the base of the leaf in treated plantlets and then they spread to the rest of the leaf. Soaking peanut with norflurazon associated with $\alpha$-tocopherol did not minimize the bleaching symptoms.

\section{Peanut plant growth on soil soaked with norflurazon or norflurazon in combination with a-tocopherol}

We measured plant growth over 30 days and compared control plants with plants growing in norflurazon-polluted soil (Fig. 1A). Control plants reached an average $10.65( \pm 1.05) \mathrm{cm}$

Norflurazon at the concentration of $100 \mu \mathrm{M}$ had a severe effect on plant growth; it induced a decrease in size (67\%) and dry weight (49\%) (Fig. 1A, B) which can be due to a probable perturbation in the energetic metabolism. Leaf area in control seedlings was of $22.85 \pm 6.36$ $\mathrm{cm}^{2}$, while in norflurazon treated seedlings it decreased 

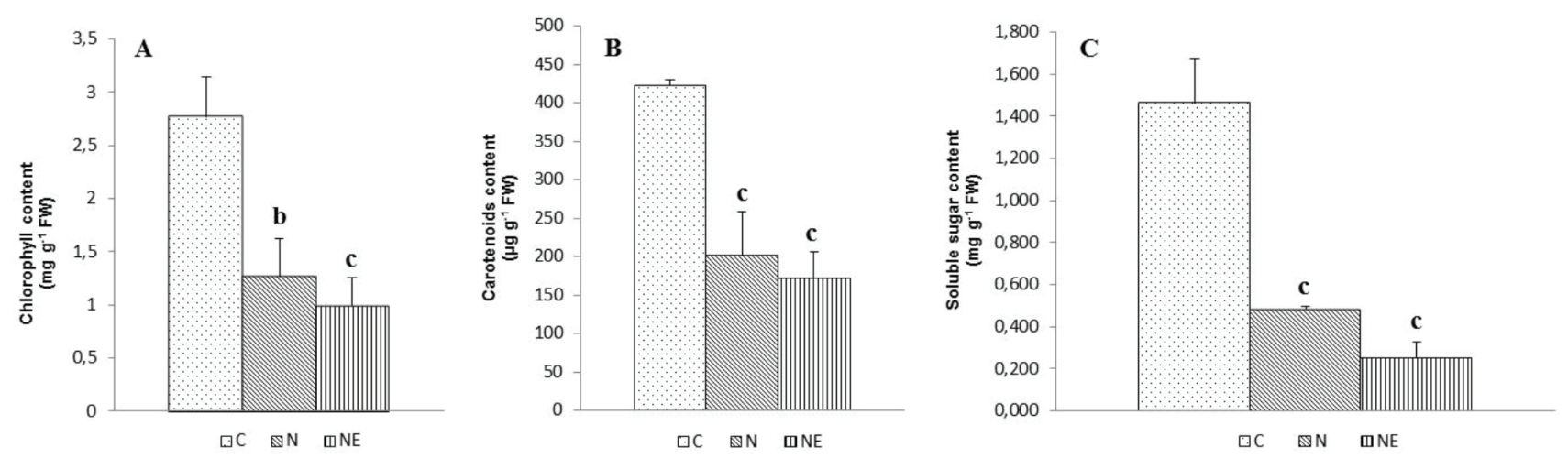

Figure 2. Effects of norflurazon on the content of total chlorophyll (A), carotenoids (B) and soluble sugar (C) in peanut plants. C: control; N: 100 $\mu \mathrm{M}$ norflurazon; NE: $100 \mu \mathrm{M}$ norflurazon $+0.25 \mathrm{mM}$ a-tocopherol. Letters indicate the significant differences between the treatments and the control. a: significant $(P<0.05)$; b: very significant $(P<0.01)$; c: highly significant $(P<0.001)$.

very significantly (52\%) compared to the control (Fig. 1C). Furthermore, the association of norflurazon with $\alpha$-tocopherol, did not ameliorate the growth of peanut seedlings.

\section{Content of chlorophyll, carotenoids and soluble sugars in plants exposed to norflurazon or norflurazon com- bined with a-tocopherol}

Thirty days after treatment, we quantified photosynthetic pigments. From $2.77 \mathrm{mg} \mathrm{g}^{-1} \mathrm{FW}$ of chlorophyll in control plants, chlorophyll content was 54 and 64\% less in plants grown on norflurazon alone or in combination with $\alpha$-tocopherol, respectively (Fig. 2A). Concurrently, we found that plants grown in presence of norflurazon alone or combined with $\alpha$-tocopherol accumulated less of carotenoids 50\% to that of control plants (202.03 and $172.37 \mu \mathrm{g} \mathrm{g}^{-1} \mathrm{FW}$ compared to $423.57 \mu \mathrm{g} \mathrm{g}^{-1} \mathrm{FW}$ in control plants)(Fig. 2B). Figure 2C showed that the soluble sugar content in the leaves of control plants was $1.46 \pm 0.21$ $\mathrm{mg} \mathrm{g}^{-1} \mathrm{FW}$. In the presence of norflurazon, this amount significantly reduced to $0.48 \pm 0.01 \mathrm{mg} \mathrm{g}^{-1} \mathrm{FW}$. The application of $\alpha$-tocopherol associated with norflurazon decreased the level of soluble sugars to $0.25 \pm 0.07 \mathrm{mg}$ $\mathrm{g}^{-1} \mathrm{FW}$ corresponding to relatively $82 \%$ of reduction to control plants.

\section{Norflurazon induced oxidative damage in lipids}

The basal level of MDA which was $0.09 \mathrm{nmol} \mathrm{g}^{-1}$ in control seedlings, increased to $55 \%$ with $100 \mu \mathrm{M}$ norflurazon treatment; the presence of $\alpha$-tocopherol lowered the magnitude of increasing MDA to 22\% (Fig. 3).

\section{Norflurazon modified non enzymatic antioxidant levels}

$\alpha$-tocopherol content in the control plants was $0.34 \pm$ $0.00 \mathrm{mg} \mathrm{g}^{-1} \mathrm{FW}$, this content decreased in the presence of norflurazon treated plants to $0.18 \pm 0.08 \mathrm{mg} \mathrm{g}^{-1} \mathrm{FW}$ corresponding to $47 \%$ of reduction; exogenous application of $\alpha$-tocopherol did not change the level of endogenous $\alpha$-tocopherol in the norflurazon treated plants which was $0.20 \pm 0.08 \mathrm{mg} \mathrm{g}^{-1} \mathrm{FW}$ (Fig. 4A).

Analysis of ascorbic acid content in leaves of control seedlings, revealed an amount of $1.90 \mu \mathrm{mol} \mathrm{g}^{-1} \mathrm{FW}$ of this soluble antioxidant, while, norflurazon treatment resulted in no significant accumulation of ascorbic acid contents compared to controls (Fig. 4B). The presence of $\alpha$-tocopherol associated with norflurazon greatly elevated the level of ascorbic acid to $>2$-fold more $\left(3.81 \mu \mathrm{mol} \mathrm{g}^{-1}\right.$ FW) (Fig. 4B). GSH content in leaves (Fig. 4C) increased for norflurazon (93\%) or norflurazon in association with $\alpha$-tocopherol treatment (18\%) comparatively to control

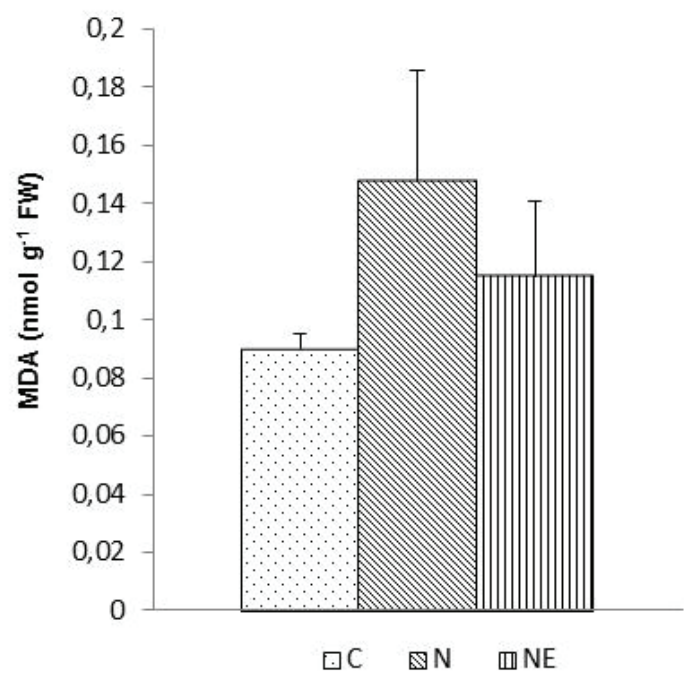

Figure 3. Effects of norflurazon on the content of MDA in peanut plants. C: control; N: $100 \mu \mathrm{M}$ norflurazon; NE: $100 \mu \mathrm{M}$ norflurazon + $0.25 \mathrm{mM}$ a-tocopherol. 

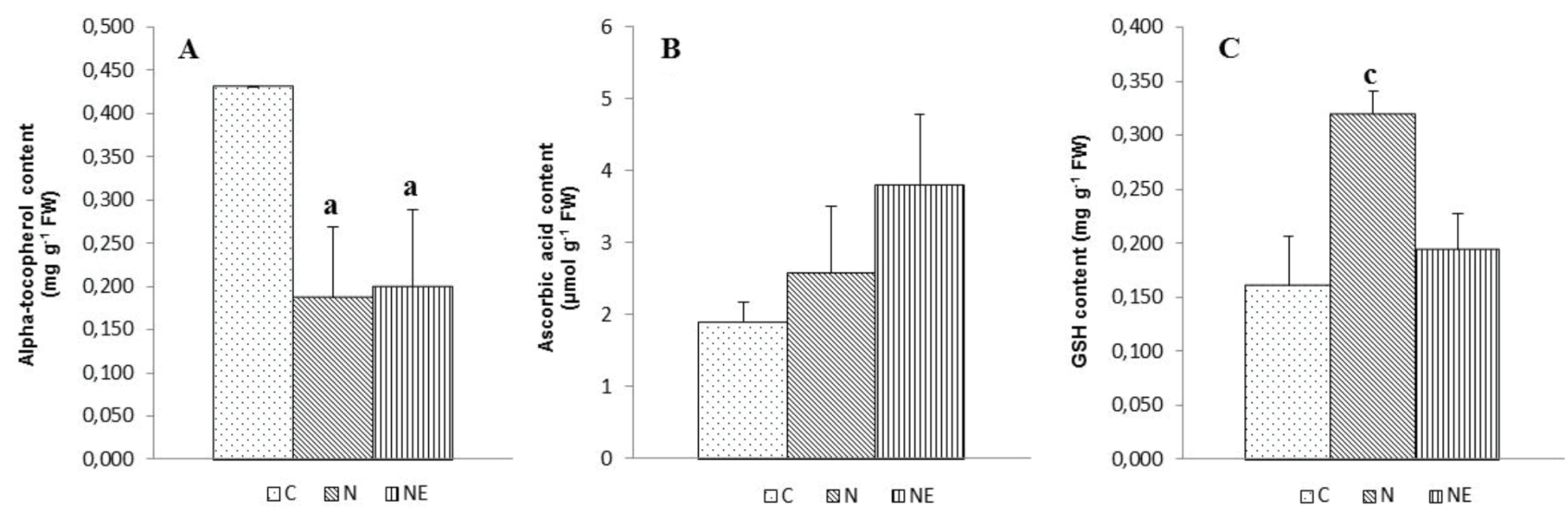

Figure 4. Effects of norflurazon on the content of a-tocopherol (A), ascorbic acid (B) and reduced glutathione (GSH) (C) in peanut plants. C: control; $\mathbf{N}: 100 \mu \mathrm{M}$ norflurazon; NE: $100 \mu \mathrm{M}$ norflurazon $+0.25 \mathrm{mM}$ a-tocopherol. Letters indicate the significant differences between the treatments and the control. a: significant $(P<0.05)$; b: very significant $(P<0.01)$; c: highly significant $(P<0.001)$.

seedlings.

\section{Norflurazon Induced changes in glutathione S-trans- ferase (GST) activity}

GST activity was $>4$-fold higher in leaves compared to roots ( 0.38 and $0.095 \mathrm{mmol} \mathrm{mn}^{-1} \mathrm{mg}^{-1}$ respectively) (Fig. 5). In leaves, the herbicide application resulted in decreasing of GST activity which was lowered to $50 \%$. In the presence of norflurazon associated with $\alpha$-tocopherol, the GST activity was also reduced by about $57 \%$ compared to the control (Fig. 5A). In roots, variation of GST activity followed no significant decrease for the application of norflurazon alone. GST activity, however, decreased for the application of norflurazon in association with $\alpha$-tocopherol with a $55 \%$ lower level than in the control (Fig. 5B).

\section{Discussion}

Norflurazon is a phytoene desaturase inhibitor which catalyzes a rate-limiting step in carotenoid biosynthesis. In the present study, symptoms of norflurazon toxicity (bleaching of foliage) were apparent after a $100 \mu \mathrm{M}$ treatment. These symptoms also occurred at $0.25 \mathrm{mM}$ of $\alpha$-tocopherol associated with norflurazon. Depigmentation or photobleaching was the main morphological symptom observed after treatment with some herbicides such as e.g., norflurazon, amitrole, and acifluorfen (Scalla 1991).

Our results showed that $100 \mu \mathrm{M}$ of norflurazon had an overall negative effect on peanuts growth. Other plant species, such as maize growing in the presence of norflurazon, also displayed a growth reduction (DallaVecchia et al. 2001). Furthermore, other herbicides such as R-40244 (St John 1985), amitrole (DallaVecchia et al. 2001), chlortoluron (Song et al. 2007), isoproturon (Nemat Alla and Hassan 2014), bentazone (Khan et al. 2004), pendimethalin (Wágner and Nádasy 2006), chlorimuron-ethyl (Scarponi et al. 1998) showed also a growth-reducing effects on their studied plants. At the concentration of 100 $\mu \mathrm{M}$, norflurazon reduced the content of photosynthetic pigments in peanut seedlings. This was in accordance with previous findings using substituted pyridazinones (Lichtenthaller and Klendgen 1977).

The decrease in carotenoids that we observed was due to the inhibition of desaturation of phytoene to phytofluene, which has resulted in phytoene accumulation (Linden et al. 1990). Because of carotenoids' conjugated double bonds, they are the most abundant quenchers of ${ }^{1} \mathrm{O}_{2}$ in the pigment bed of the photosynthetic apparatus (Young 1991), so their absence lead to the formation of active oxygen molecules (Jung et al. 2000). Decrease in chlorophylls content observed in depigmented leaves of
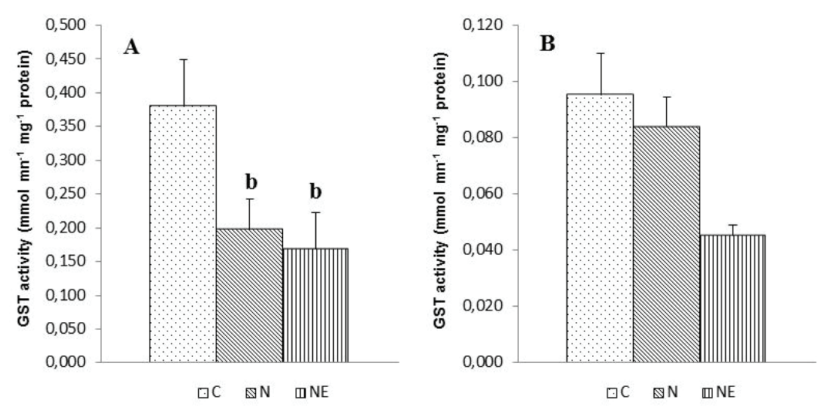

Figure 5. Effects of norflurazon on the activity of GST in leaves (A) and roots (B) on peanut plants. C: control; N: $100 \mu \mathrm{M}$ norflurazon; NE: 100 $\mu \mathrm{M}$ norflurazon $+0.25 \mathrm{mM}$ a-tocopherol. Letters indicate the significant differences between the treatments and the control. a: significant $(P$ $<0.05)$; b: very significant $(P<0.01)$; : highly significant $(P<0.001)$. 
peanut seedlings was due to photooxidation linked to the depletion of carotenoids (Dankov et al. 2009). The decrease in chlorophylls was also due to a deficiency in their biosynthesis. Oelmuller and Mohr (1986) showed that the last step of chlorophyll biosynthesis does not take place following the destruction of chloroplastic structures by the norflurazon. Interestingly, herbicides which primarily inhibit pigment biosynthesis also have a growth-reducing effect (DallaVecchia et al. 2001).

In our study, there is a positive correlation between decrease of photosynthetic pigments and level of sugar content. We can deduce that peanut plants growing in norflurazon-contaminated soil are impaired in their photosynthesis and display a reduction in growth. Similar results were obtained in maize treated with atrazine, linuron, prometryn, and pyrazon (Osman et al. 1988), wheat treated with isoproturon (Bandana, 2002) and in Vitis vinifera L. (bine) stressed with flumioxazin.

MDA, a decomposition product of polyunsaturated fatty acids hydroperoxides, has been utilized very often as a suitable biomarker for lipid peroxidation. The data presented here, show that norflurazon lead to MDA accumulation. Other herbicides as fluazifop- $p$-butyl lead to MDA increase in bristly starbur (Luo et al. 2004). Lipid peroxidation can be initiated by ROS. Norflurazon is known to induce oxidative stress in treated plants by generation of ROS that severely affects cell membranes functionality and integrity and can produce irreversible damages to the cell function (Yoshimura et al. 2004). On the other hand, Abrous-Belbachir et al. (2009) reported that norflurazon affects fatty acids (FA) composition of soybean seedlings and fatty acid desaturases resulting in a decrease in polyunsaturated fatty acids (PUFAs).

The variability in individual responses to herbicide treatment likely results from differences in either the absorption/transport of the herbicide or in metabolizing/detoxification mechanisms, such as those involving CYP450 and GST. GST activities from leaves and roots decreased in peanut seedlings after a $100 \mu \mathrm{M}$ norflurazon treatment, suggesting an overload of ROS damage. The decrease in the activity of GST in seedlings treated with norflurazon indicated that a part of this herbicide is not conjugated in roots and leaves of the treated plants. Coşkun and Zihnioğlu (2002) suggested that the GST may not be the only enzyme induced by pesticides. Several pesticides can induce in plants differentiation in the other enzyme levels, which are effective in the protective and tolerant system such as the other glutathione related enzymes, and mixed-function oxidases. The conjugation of glutathione with 1-chloro-2,4-dinitrobenzene is widely used for detecting GST activity, but it may not detect all GST isozymes (Timmerman 1989). Ascorbate and glutathione are the two soluble antioxidants that constitute the ascorbate-glutathione cycle and are involved in tocopherol regeneration from $\alpha$-tocopheroxyl radicals.

In the present study, we found that the soluble glutathione and ascorbate levels were increased in norflurazon treatment alone or combined with $\alpha$-tocopherol compared to the control plants. Ascorbic acid and reduced glutathione are accumulated in many plant species in response to abiotic stress such as herbicides and water stress (Heber et al. 1996).

Accumulation of glutathione was also observed in unchallenged Arabidopsis vte1 mutants (slightly but significantly) (Kanwischer et al. 2005) and outdoor grown Arabidopsis vte 1 and vte 4 mutants (Semchuk et al. 2009). The increased glutathione level in the norflurazon treated peanut plants could be interpreted in such a way that it may have triggered alterations in the ROS signaling networks, allowing these plants to achieve a new homeostasis to cope with the abiotic stress. Glutathione was previously proposed as a candidate transmitter of intracellular ROS signals (Foyer and Noctor 2011). The increase in ascorbate and reduced glutathione in treated peanut seedlings by the norflurazon suggests that peanut seedlings have not used these antioxidants to attenuate the deleterious effects of the herbicide. Ågren (1985) mentioned the effect of exogenous application of antioxidant compounds on the primary metabolites of various crops. Exogenous application of some antioxidants and other substances enhanced date palm plantlet tolerance to environmental stress (Awad et al. 2005).

The content of $\alpha$-tocopherol decreased in peanut seedlings subjected to norflurazon only or the combination of norflurazon and $\alpha$-tocopherol. The functions of tocopherols, especially $\alpha$-tocopherol, are recognized as lipid antioxidants with the ability to scavenge and quench various ROS and protect PUFAs from lipid peroxidation (Munné-Bosch, 2005). Tocopherol-deficient mutant showed an increase in non-enzymatic lipid peroxidation products and a range of developmental defects in early seedling growth (Sattler et al. 2006).

Differences in tocopherol content may be due to growing conditions and environmental factors, especially stress conditions (Müller 1998). An Arabidopsis double mutant lacking both vitamin $\mathrm{E}$ and the carotenoid zeaxanthin was found to be sensitive to photooxidative stress (Havaux et al. 2005), indicating that vitamin $\mathrm{E}$ and carotenoids have overlapping functions and that the phototolerance of tocopherol-deficient single mutants was actually due to an increased activity of carotenoids compensating for the loss of tocopherols. Carotenoids, tocopherols, ascorbate and glutathione are interdependent in the control of ROS levels in plants under stress conditions and thus play a role in limiting damage due to induced oxidative stress.

The chemical scavenging of ${ }^{1} \mathrm{O}_{2}$ by $\alpha$-tocopherol can 
Impact of exogenous alpha tocopherol on peanut seedlings

lead to a net tocopherol loss, since $\alpha$-tocopherol quinone and other oxidation formed products cannot be recycled back to $\alpha$-tocopherol (Munné-Bosch and Alegre 2002). Irreversible degradation of $\alpha$-tocopherol may also occur when a-tocopheroxyl radicals, which result from the scavenging of lipid peroxyl radical by $\alpha$-tocopherol, are not recycled back by ascorbate. This may occur, for example, when ascorbate availability in chloroplasts is limited (Munné-Bosch 2005). The changes in $\alpha$-tocopherol level during plant responses to environmental stresses are characterized by two phases. In the first phase $\alpha$-tocopherol levels will tend to increase and contribute to protection by reducing ROS levels and inhibiting lipid peroxidation. When the stress is too severe, tocopherol degradation exceeds its synthesis and levels decrease (phase II) (Munné-Bosch 2005). Peanut seedlings subjected to the norflurazon treatment might be in a severe phase of stress.

\section{Conclusion}

In conclusion, our results demonstrate in our culture conditions, that norflurazon at $100 \mu \mathrm{M}$ induced a lethal physiological state. Both growth and biochemical parameters are profoundly affected, leading to an adverse effect on mechanisms of detoxification. The main effect was membrane destruction linked to a lack of carotenoids and MDA accumulation. The sharp reduction in carotenoids caused by norflurazon gives rise to a damage to morphological and biochemical level sometimes not reversed by the exogenous application of $\alpha$-tocopherol.

The addition of the exogenous antioxidant $\alpha$-tocopherol did not alleviate the phytotoxicity of norflurazon although we observed a decrease in MDA content. This result indicates that though $\alpha$-tocopherol may afford a certain degree of protection against stress conditions, this protection is limited by the amount of other antioxidants present in membranes and/or by the ROS. As in the cases of the other antioxidants, the level of tocopherol is the result of synthesis, recycling and degradation (consumption).

In our conditions, it can be concluded that exogenous tocopherol has assumed its role as protectant of lipid peroxidation. But it seems that both carotenoids and tocopherols are required to overcome the stress which explains that the sharp decline in carotenoids by the norflurazon has significantly affected the growth and physiology of seedlings of peanut despite the presence of exogenous $\alpha$-tocopherol.

\section{References}

Abrous-Belbachir O, De Paepe R, Tremolières A, Mathieu C, Aïd F, Benhassaine-Kesri G (2009) Evidence that norflurazon affects chloroplast lipid unsaturation in Soybean leaves (Glycine max L.). J Agric Food Chem 57:11434-11440.

Ågren GI (1985) Limits to plant production. J Theor Biol 113:92-98.

Apel K, Hirt H (2004) Reactive oxygen species: metabolism, oxidative stress, and signal transduction. Annu Rev Plant Biol 55:373-399.

Awad AM, Soaud AA, El-Konaissi MS, Zaid A, Eshkandi $\mathrm{OH}$, Badawi MA (2005) Effect of elemental sulfur, some antioxidants and growth regulators on tolerance ability of in vitro produced plantlets and nutrient uptake, yield and fruit quality of mature date palm trees Part I. Tolerance ability of in vitro produced plantlets. The sixth Annual Research Conference at UAE University, 24-26 April, 2005.

Bandana SN (2002) Chlorophyll and sugar content in wheat leaves as influenced by isoproturon application and its relationship with grain sugar content. Indian J Plant Physiol 7:401-403.

Bhatnagar-Mathur P, Devi MJ, Reddy DS, Lavanya M, Vadez V, Serraj R, Yamaguchi-Shinozaki K, Sharma KK (2007) Stress inducible expression of At DREB1A in transgenic peanut (Arachis hypogaea L.) increases transpiration efficiency under water-limiting conditions. Plant Cell Rep 26:2071-2082.

Bradford MM (1976) A rapid and sensitive method for the quantitation of microgram quantities of protein utilizing the principle of protein-dye binding. Anal Biochem 72:248-259.

Breitenbach J, Zhu C, Sandmann G (2001) Bleaching herbicide norflurazon inhibits phytoene desaturase by competition with the cofactors. J Agric Food Chem 49:5270-5272.

Coşkun G, Zihnioğlu F (2002) Effect of some biocides on glutathione-s-transferase in barley, wheat, lentil and chickpea plants. Turk J Biol 26:89-94.

Dalla Vecchia F, Barbato R, La Rocca N, Moro I, Rascio N (2001) Responses to bleaching herbicides by leaf chloroplasts of maize plants grown at different temperatures. Journal of Experimental Botany 52:811-820.

Dankov K, Busheva M, Stefanov D, Apostolova EL (2009) Relationship between the degree of carotenoid depletion and function of the photosynthetic apparatus. J Photochem Photobiol B: Biology 96:49-56.

Doulis AG (1994) Antioxidant responses of pea (Pisum sativum L.) Protoplasts. PhD. PPWS, Virginia Tech.

Ellman GL (1959) Tissue sulfhydryl groups. Arch Biochem Biophys 82:70-77. 
Foyer CH, Noctor G (2011) Ascorbate and glutathione: the heart of the redox hub. Plant Physiol 155:2-18.

Habig WH, Pabst MJ, Jakoby WB (1974) Glutathione S-transferases. The first step in mercapturic acid formation. J Biol Chem 249:7120-7130.

Havaux M, Eymery F, Porfirova S, Rey P, Dörmann P (2005) Vitamin E protects against photoinhibition and photooxidative stress in Arabidopsis thaliana. Plant Cell 17:3451-3469.

Heber U, Miyake C, Mano J, Ohno C, Asada K (1996) Monodehydroascorbate radical detected by electron paramagnetic resonance spectrometry is a sensitive probe of oxidative stress in intact leaves. Plant Cell Physiol 37:1066-1072.

Hess JL (1993) Vitamin E, $\alpha$-tocopherol. In:R.G. Alscher and J.L. Hess (eds.) Antioxidants in higher plants. CRC press, Inc. Boca Rarton, Florida, 111-134.

Higgins LG, Hayes JD (2011) Mechanisms of induction of cytosolic and microsomal glutathione transferase (GST) genes by xenobiotics and pro-inflammatory agents. Drug Metab Rev 43:92-137.

Hodges M, Andrews D, Johson J, Hamilton I (1996) Antioxidant compound responses to chilling stress in differentially sensitive inbred maize lines. Phys Plant 98:685-692.

Jung SY, Kim JS, Cho KY, Tae GS, Kang BG (2000) Antioxidant responses of cucumber (Cucumis sativus) to photoinhibition and oxidative stress induced by norflurazon under high and low PPFDs. Plant Sci 153:145-154.

Kanwischer M, Porfirova S, Bergmüller E, Dörmann P (2005) Alterations in tocopherol cyclase activity in transgenic and mutant plants of Arabidopsis affect tocopherol content, tocopherol composition, and oxidative stress. Plant Physiol 137:713-723.

Karuppanapandian T, Moon JC, Kim C, Manoharan K, Kim W (2011) Reactive oxygen species in plants: their generation, signal transduction, and scavenging mechanisms. Aust J Crop Sci 5:709-725.

Khan MS, Zaidi A, Aamil M (2004) Influence of herbicides on chickpea-Mesorhizobium symbiosis. Agronomie 24:123-127.

Lichtenthaller HK, Klendgen HK (1977) Effect of the herbicide San 6706 on biosynthesis of photosynthetic pigments and prenyl quinones in hordeum seedlings. $Z$ Naturforsch 32:236-240.

Lichtenthaler HK (1987) Chlorophylls and carotenoids: Pigments of Photosynthetic Biomembranes. Method Enzymol 148:350-382.

Linden H, Sandmann G, Chamouitz D, Hirschber GJ, Boger P (1990) Biochemical characterisation of synechoccus mutants selected against the bleaching herbicide norflurazon. Pestic Biochem Physiol 36:46-51.

Luo XY, Sunohara Y, Matsumoto H (2004) Fluazifop-butyl causes membrane peroxidation in the herbicide-susceptible broad leaf weed bristly starbur (Acanthospermum hispidum). Pestic Biochem Physiol 78:93-102.

McCready RM, Guggolz JJ, Silviera V, Owens HS (1950) Determination of starch and amylose in vegetables. Anal Chem 22:1156-1160.

Mène-Saffrané L, DellaPenna D (2010) Biosynthesis, regulation and functions of tocochromanols in plants. Plant Physiol Biochem 48:301-309.

Mittler R, Vanderauwera S, Gollery M, Van Breusegem F (2004) Reactive oxygen gene network of plants. Trends Plant Sci 9:490-498.

Müller H (1998) Drought-induce photooxidative stress and the role of antioxidative defence systems in drought tolerance of wheat genotypes. Universität Hohenheim.

Munné-Bosch S (2005) The role of $\alpha$-tocopherol in plant stress tolerance. J Plant Physiol 162:743-748.

Munné-Bosch S, Alegre L (2002) Interplay between ascorbic acid and lipophilic antioxidant defences in chloroplasts of water-stressed Arabidopsis plants. FEBS Lett 524:145-148.

Nemat Alla MM, Hassan NM (2014) Alleviation of isoproturon toxicity to wheat by exogenous application of glutathione. Pestic Biochem Physiol 112:56-62.

Oelmuller R, Mohr H (1986) Photooxidative destruction of chloroplasts and its consequences for expression of nuclear genes. Planta 167:106-113.

OertliJJ (1987) Exogenous application of vitamins as regulators for growth and development of plants: a review. Z Pflanzenernähr Bodenk 150:375-391.

Osman RO, Ahmed FA, Khalil FA, Ali MS (1988) Effect of some herbicides as plant growth regulators on the chemical composition of Zea mays grains. Food Chem 28:167-176.

Sattler SE, Gilliland LU, Magallanes-Lundback M, Pollard M, DellaPenna D (2004) Vitamin E is essential for seed longevity and for preventing lipid peroxidation during germination. Plant Cell 16:1419-1432.

Sattler SE, Mène-Saffrané L, Farmer EE, Krischke M, Mueller MJ, DellaPenna D (2006) Non-enzymatic lipid peroxidation reprograms gene expression and activates defense markers in Arabidopsis tocopherol-deficient mutants. Plant Cell 18:3706-3720.

Scalla R (1991) Les herbicides: mode d'action et principes d'utilisation. INRA, Paris.

Scarponi L, Younis ME, Standardi A, Martinetti L, Hassan NM (1998) Changes in carbohydrate formation and starch symptoms in Vicia faba L. treated with propachlor, chlorimuron-ethyl and imazethapyr. Agric Med 128:118-125.

Semchuk NM, Lushchak OV, Falk J, Krupinska K, Lushchak VI (2009) Inactivation of genes, encoding tocopherol biosynthetic pathway enzymes, results in oxidative stress in outdoor grown Arabidopsis thaliana. Plant Physiol 
Biochem 47:384-390.

Sinnhuber RO, Yu TC (1958) Characterization of the red pigment formed in 2-thiobarbituric acid determination of oxidative rancidity. J Food Sci 23:626-633.

Song NH, Yin XL, Chen GF, Yang H (2007) Biological responses of wheat (Triticum aestivum) plants to the herbicide chlorotoluron in soils. Chemosphere 68:1779-1787.

St John JB (1985) Action of R-40244 on chloroplast pigments and polar lipid. Pestic Biochem Physiol 23:13-18.

Szymańska R, Kruk J (2008) Tocopherol content and isomers' composition in selected plant species. Plant Physiol Biochem 46:29-33.

Timmerman KP (1989) Molecular characterization of corn glutathione-s-transferase isozymes involved in herbicide detoxication. Physiol Plant 77:465-471.
Vencill WK (2002) Herbicide handbook. Weed Science Society of America, Lawrence.

Wágner G, Nádasy E (2006) Effect of pre-emergence herbicides on growth parameters of green pea. Commun Agric Appl Biol Sci 71:809-813.

Yoshimura K, Miyao K, Gaber A, Takeda T, Kanaboshi H, Miyasaka H, Shigeoka S (2004) Enhancement of stress tolerance in transgenic tobacco plants overexpressing Chlamydomonas glutathione peroxidase in chloroplasts or cytosol. Plant J 37:21-33.

Young AJ (1991) The photoprotective role of carotenoids in higher plants. Physiol Plant 83:702-708. 
